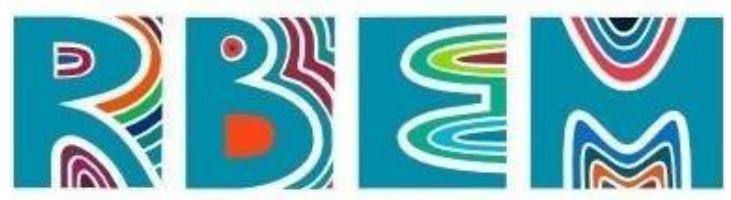

REVISTA BAIANA DE EDUCAÇÃO MATEMÁTICA

\title{
ARTIGO
}

dol http://dx.doi.org/10.47207/rbem.v1i0.9301

\section{MODELAGEM MATEMÁTICA E FILOSOFIA DA LINGUAGEM: ALGUMAS ARTICULAÇÕES}

\author{
CALDEIRA, Ademir Donizeti \\ Universidade Federal de São Carlos (UFSCar). Doutor em Educação pela Universidade de Campinas (Unicamp). \\ ORCID: https://orcid.org/0000-0003-0290-9851. E-mail: mirocaldeira@gmail.com
}

\section{COSTA, Daniana de}

Universidade Federal de São Carlos (UFSCar). Mestre em Desenvolvimento Regional (Educação e Desenvolvimento) pela Universidade Tecnológica Federal do Paraná (UTFPR). ORCID: https://orcid.org/00000002-8523-6156. E-mail: danianadecosta@yahoo.com.br.

\section{CAMBI, Betina}

Universidade Federal de São Carlos (UFSCar). Doutora em Educação pela Universidade Federal de São Carlos (UFSCar). ORCID: https://orcid.org/0000-0002-1766-022X. E-mail: betinacambi@ yahoo.com.br.

Resumo: O objetivo deste artigo é realizar um estudo sobre como alguns termos que pertencem ao âmbito da Modelagem Matemática estão sendo pautados no pensamento de Ludwig Wittgenstein. A metodologia baseia-se na pesquisa bibliográfica e o material de análise é constituído por oito artigos científicos que foram publicados em congressos e em periódicos. Pelo estudo realizado, evidenciaramse termos da Modelagem, tais como: matemática, realidade, modelo, matematização e inteiração, os quais apresentaram um entrelaçamento discursivo com a filosofia da linguagem de Wittgenstein. Constatou-se que tal entrelaçamento ocorre por meio da atividade, ou seja, "ao modelar" é possível detectar como os modeladores articulam tais termos e como os percebem.

Palavras-chave: Ludwig Wittgenstein. Linguagem. Modelagem Matemática.

\section{MATHEMATICAL MODELING AND THE PHILOSOPHY OF LANGUAGE: SOME ARTICULATIONS}

\begin{abstract}
The objective of this article is to realize a study on how some terms, which belong to the scope of Mathematical Modeling, are being guided by Ludwig Wittgenstein's thinking. The methodology is based on bibliographic research and the analysis material consists of eight scientific articles that have been published in congresses and journals. Through the study realized, terms of Modeling were evidenced, such as: mathematics, reality, model, mathematization and to be acquainted with, which presented a discursive interlacing with Wittgenstein's philosophy of language. It was found that such interlacing occurs through activity, that is, "when modeling" it is possible to detect how the modelers articulate such terms and how they perceive them.
\end{abstract}

Keywords: Ludwig Wittgenstein. Language. Mathematical Modeling.

\section{MODELACIÓN MATEMÁTICAS Y LA FILOSOFÍA DEL LENGUAJE: ALGUNAS ARTICULACIONES}




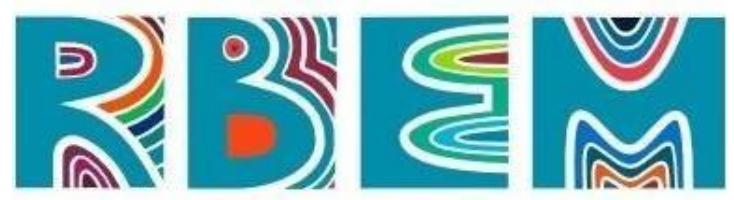

REVISTA BAIANA DE EDUCAÇÃO MATEMÁTICA

Resumen: El propósito de este artículo es realizar un estudio sobre cómo algunos términos, que pertenecen al Modelación Matemáticas, están siendo guiados por el pensamiento de Ludwig Wittgenstein. La metodología se basa en la investigación bibliográfica y el material de análisis consta de ocho artículos científicos que han sido publicados en congresos y revistas. A través del estudio realizado, se evidenciaron términos de modelado, tales como: matemáticas, realidad, modelo, matematización e interacción, que presentaban un entrelazamiento con la filosofía del lenguaje de Wittgenstein. Se descubrió que presentaban un entrelazamiento discursivo se produce a través de la actividad, o sea, "al modelar" es posible detectar cómo los modeladores articulan esos términos y cómo los perciben.

Palavras-clave: Ludwig Wittgenstein. Lenguaje. Modelación Matemáticas

\section{E se notarmos a linguagem...}

Questionamentos tais como o que é a linguagem e como é possível que ela signifique algo fazem parte do pensamento do filósofo austríaco Ludwig Wittgenstein (MORENO, 2000). De fato, indagações como essas e outras que também estão no campo da linguagem, ou que relacionam essa temática com outras áreas do saber, despertam a curiosidade e/ou intrigam o ser humano. Ora, não é de se estranhar que a linguagem provoque tal 'vontade de saber', mas isso acontece se ela não passar despercebida pelo fato de ser corriqueira, comum e do cotidiano.

A linguagem está muito presente na vida diária e é inevitavelmente necessária. A comunicação, as relações sociais, o pensamento, a elaboração e expressão de conceitos ou ideias, a compreensão de comportamentos e o acesso à realidade se dão por meio de trocas simbólicas, ou seja, por meio da linguagem (ARAÚJO, 2004).

Diante do exposto, filósofos contemporâneos, tais como Ludwig Wittgenstein e Michel Foucault, por exemplo, dedicaram tempo para notar a importância da linguagem e ali exercer uma atividade filosófica. Deste modo, pode-se dizer que a linguagem já não é mais 'despercebida'. Agora, sob a ótica da filosofia, ela torna-se complexa, no sentido de que, ao ser posta sob tarefa filosófica, tem-se como objetivo a busca de razões e causas de algo que outrora poderia ter sido considerado como banal.

\section{Modelagem Matemática e a dimensão discursiva}




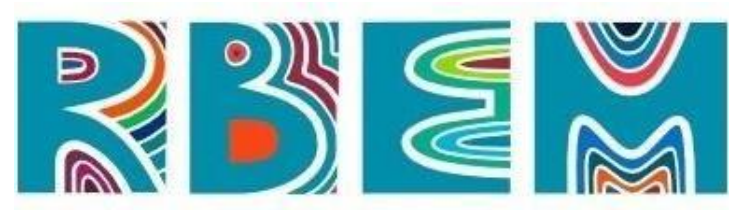

REVISTA BAIANA DE EDUCAÇÃO MATEMÁTICA

A Modelagem Matemática é hoje um campo de pesquisa organizado e consolidado, no qual há vasta literatura sobre o que ela é, bem como as formas de desenvolvê-la ou pensá-la. Esse processo histórico de sua afirmação é marcado pelo final da década de 1990, a partir de movimentos de mudanças que giraram, principalmente, em torno da organização e composição curricular (QUARTIERI; KNIJNIK, 2012).

O seu processo de surgimento e desenvolvimento no cenário educacional como um acontecimento, no entanto, não é tão natural e despretensioso. Magnus (2018) nos mostra que a emergência da Modelagem é potencializada pela instauração da percepção de uma crise no ensino de Matemática, a qual foi impulsionada pela circulação de um conjunto de ideias, mas, principalmente, pelo entendimento de que aprender Matemática é difícil e que a matemática escolar está distante da realidade dos alunos. Tais ideias, por sua vez, emergem a partir do engendramento de diferentes campos do conhecimento, tais como o econômico, o político e o educacional, que se mostram no contexto histórico do país nas décadas de 1980 e 1990 e se entrelaçam, constituindo um mecanismo que cria condições para o 'nascimento da Modelagem' como uma nova forma de ensino, uma nova proposta para contribuir na solução da crise no ensino de Matemática.

Dessa forma, a Modelagem foi organizando-se e estabeleceu suas estruturações a partir de uma produção teórica, educacional, econômica, social, política e cultural, produzindo um desdobramento sobre 'como' desenvolver atividades de Modelagem. Tal desdobramento abrange investigações que se estendem desde os aspectos processuais de desenvolvimento à sua implementação em sala de aula, como explicitado, por exemplo, em Barbosa (2001), aspectos da formação de professores (ROSA, 2013), ou direções que se entrelaçam com o campo da filosofia (MAGNUS; CALDEIRA; DUARTE, 2019) ou, ainda, mais especificamente da filosofia da linguagem (MARON, 2017). A partir disso, ocorre uma sistematização de mecanismos que não constituem apenas a sua prática, mas sua relação com diferentes aspectos, tais como: o professor, o aluno, a dinâmica escolar, o currículo, dentre outros.

Além desse desdobramento, a Modelagem apresenta ideias que convergem a uma unidade de pensamento - denominada aqui de unidade discursiva - em relação àquilo que se constitui como a própria Modelagem. Ou seja, existe uma unidade em relação às formas que a constitui, visto que, por meio da linguagem matemática de um problema que seja fruto da 


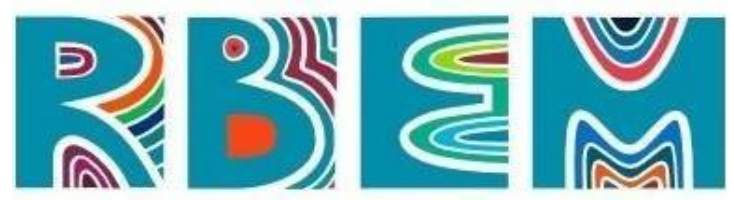

REVISTA BAIANA DE EDUCAÇÃO MATEMÁTICA

realidade do aluno, caracteriza-se o aspecto central do desenvolvimento de atividades de Modelagem.

Ao possibilitar, dessa forma, por meio de atividades de Modelagem, que situações cotidianas da realidade sejam trabalhadas em sala de aula, a Matemática passa a ser uma ferramenta por meio da qual seja possível compreender as inter-relações entre diferentes aspectos do mundo, sejam econômicos, sociais, científicos ou tecnológicos, caracterizando-se como uma outra proposta para o seu ensino.

Diante disso, as atividades de Modelagem abrem a possibilidade de significação do conteúdo matemático a partir do que é vivido pelo aluno, de modo que a sua experiência possa ser um caminho para que a linguagem matemática seja desenvolvida, por meio de um modelo mais elaborado ou por meio de algum tipo de representação matemática que simbolize o problema tratado a partir da sua vivência.

A concretização dessa significação desencadearia, também, outros aspectos, como o grau de aprofundamento que o professor dará para o problema discutido; de quais serão as relações estabelecidas entre o problema estudado e o conteúdo de matemática; do diálogo entre professor e aluno acerca do problema e da matemática; e não, exclusivamente, pelo desenvolvimento da atividade e de Modelagem. Assim, a possibilidade de um espaço para reflexão seria aberta, a partir do qual os alunos, possivelmente, compreenderiam melhor as situações que os cercam.

Diante do exposto, compreende-se que a Modelagem foi criada e estruturada por esta produção teórica - e discursiva -, a qual a delimita e a caracteriza enquanto Modelagem. $\mathrm{Ou}$ seja, há a instauração de um discurso, no qual a Modelagem é "produzida pelo discurso [...] é objeto do discurso" (CALDEIRA; MAGNUS; CAMBI, 2018, p. 28), uma vez que tais discursos são "práticas que formam sistematicamente os objetos de que falam" (FOUCAULT, 2014, p. 60).

Isso nos mostra que não há preocupações com a linguagem em si, sua estrutura, organização, mas há preocupação com a "existência dos discursos, pelo fato das palavras terem surgido" (FOUCAULT, 2013, p. 74), por todo potencial, por toda força de elaboração e construção que a linguagem possibilita em seus usos.

Isso significa que, de acordo com Veiga-Neto (2014), Foucault compreende a linguagem como um instrumento que liga o nosso pensamento à coisa pensada, numa espécie 


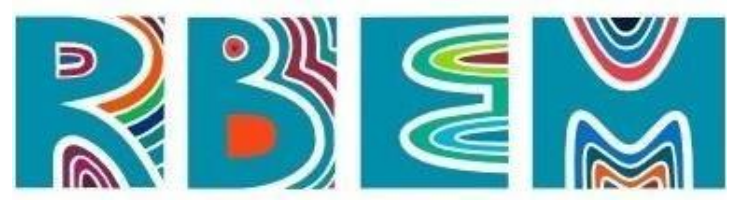

REVISTA BAIANA DE EDUCAÇÃO MATEMÁTICA

de instrumento de correspondência e como formalização do pensar: a linguagem é constitutiva do nosso pensamento e se expressa para manifestar e traduzir o querer fundamental daqueles que falam. Assim, a principal questão é o uso e o funcionamento histórico da linguagem, uma vez que a "língua é um conjunto de estruturas, mas os discursos são unidades de funcionamento, e a análise da linguagem em sua totalidade não pode deixar de fazer face a essa exigência essencial” (FOUCAULT, 2013, p. 75), ou seja, não pode negar as conexões e relações com o mundo.

Compreender a Modelagem numa dimensão discursiva, a partir de Foucault, para realizar o estudo desejado, torna-se possível pois tanto Foucault quanto Wittgenstein “[...] dão as costas para a busca de uma suposta razão pura e voltam-se para a análise das relações da linguagem consigo mesma e das relações entre a linguagem e o mundo" (VEIGA-NETO, 2014, p. 90-91), desenvolvendo um pensamento no qual a linguagem depende do contexto de seus usos.

Assim, entende-se que um estudo da Modelagem a partir da filosofia da linguagem possa caracterizar-se como possibilidade de mobilizar e dar visibilidade a uma outra forma de pensá-la, de modo que também poderá marcar e delimitar aspectos que a envolvam e que podem reconfigurar os significados atribuídos aos seus próprios elementos por meio de um entrelaçamento entre os campos da Educação Matemática e da Filosofia.

Portanto, ao partir da compreensão de que é a constituição e circulação de um discurso que dará vida à Modelagem e que esse discurso pode ser constituído por meio de diferentes campos de conhecimento (filosofia, formação de professores, ensino e aprendizagem, por exemplo), o objetivo deste artigo é realizar um estudo sobre como alguns termos que pertencem ao âmbito da Modelagem estão sendo discutidos e organizados em pesquisas da sua área pautadas no pensamento do segundo ${ }^{1}$ Ludwig Wittgenstein, seja na elaboração de atividades de Modelagem ou por meio de suas interpretações de trabalhos de outros autores da referida temática.

\section{Uma breve síntese do pensamento do segundo Wittgenstein}

\footnotetext{
${ }^{1}$ Refere-se ao segundo Wittgenstein (Wittgenstein II), um dos expoentes da virada linguística. A vertente do Wittgenstein I é lógico-formal, está apresentada em sua obra Tractatus Logico-Philosophicus, a do segundo Wittgenstein é pragmática e consta nas Investigações Filosóficas (ARAÚJO, 2004).
} 


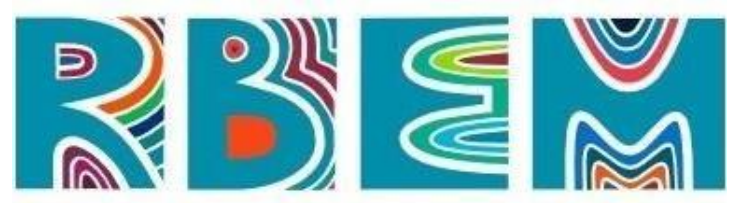

REVISTA BAIANA DE EDUCAÇÃO MATEMÁTICA

Historicamente, "até o século XIX, a linguagem foi praticamente ignorada [...]" (ARAÚJO, 2004, p. 19), foi somente no final do século XIX que começaram a surgir novas reflexões sobre ela, as quais foram reunidas pela expressão denominada virada linguística (GOTTSCHALK, 2007).

Segundo Araújo (2004), a virada linguística provocou transformações rápidas na linguística e na filosofia da linguagem, de tal modo que a linguagem não é mais considerada apenas como representação das coisas no pensamento, como "[...] um veículo que carrega e representa nossas ideias, num lugar marginal em relação ao mundo que ele descreve ou ao sujeito que a usa" (VILELA; MENDES, 2011, p. 8). No lugar da análise de representações passa a existir a análise da linguagem, a qual é "vista em termos de atividade, como constitutiva das coisas" (VILELA; MENDES, 2011, p. 8).

Em sua segunda fase, Wittgenstein desenvolveu novos conceitos, tais como o de jogo de linguagem ${ }^{2}$ - no qual o uso das palavras dentro do seu contexto linguístico é colocado em evidência: “[...] os jogos de linguagem se referem à linguagem usada em contextos específicos, por falantes e ouvintes específicos" (MARCONDES, 2009, p. 169) - e o de semelhança de família, que se refere aos traços comuns existentes entre jogos de linguagens (WITTGENSTEIN, 2009a). Desse modo, a linguagem não está mais relacionada com a análise lógica de proposições, conforme as concepções neoplatônicas do primeiro Wittgenstein. Agora,

[...] Wittgenstein se afasta do idealismo por não crer na essência do significado e, por outro lado, também do empirismo por não acreditar na existência da objetividade dos fatos ou do objeto. Para este filósofo, o significado e, por conseguinte o conhecimento, se dá no uso que fazemos da linguagem em uma dada forma de vida [...] (DUARTE; TASCHETTO, 2019, p. 55).

Na obra Investigações Filosóficas, Wittgenstein (2009a) esclarece que o significado dos conceitos não está no próprio objeto, mas que é definindo a posteriori por meio dos seus usos e são as formas de vida - "diversas atividades humanas" (GOTTSCHALK, 2016, p. 55)

\footnotetext{
${ }^{2}$ O itálico será utilizado, ao longo deste artigo, para tomadas conceituais, palavras estrangeiras e menção a títulos de obras; já as aspas simples estão sendo empregadas para marcação de sentidos.
} 


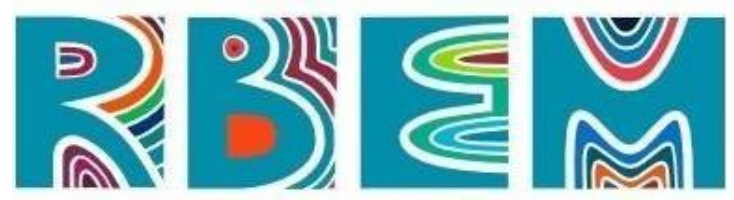

REVISTA BAIANA DE EDUCAÇÃO MATEMÁTICA

- que mostram como a linguagem funciona. A significação de uma palavra depende, portanto, do seu contexto de uso. Além disso, as diversas aplicações de uma palavra permitem que venha à tona o conceito de algo que passa a organizar a experiência das pessoas (GOTTSCHALK, 2007).

Ademais, quando se trata do conceito de algo, é importante esclarecer que "o conceito é, assim, um referencial, um instrumento mais ou menos preciso - uma norma, no caso da Matemática, uma regra apenas indicativa, em outros casos - que convencionamos para organizar nossa experiência” (MORENO, 1995, p. 33).

Gottschalk (2008) nos informa que no início da década de 1930, Wittgenstein indagava-se sobre a natureza das proposições matemáticas, pois elas lhe chamavam a atenção devido ao papel que desempenhavam, o qual é diferente das demais proposições da linguagem corrente.

Na concepção de Wittgenstein, uma afirmação matemática nem sempre é produto de algum tipo de constatação, mas ela é uma certeza, uma proposição que desempenha papel normativo que organiza a experiência empírica do ser humano. Ele observou que as proposições matemáticas são utilizadas como normas que têm “[...] função paradigmática, ou seja, são vistas por Wittgenstein como regras de como proceder” (GOTTSCHALK, 2008, p. 81, grifo da autora).

Depois de apresentar brevemente a Modelagem e um panorama conciso sobre as ideias da filosofia do segundo Wittgenstein, passa-se, nas próximas seções, à exposição da metodologia utilizada para a construção deste artigo, bem como seus dados, as discussões e conclusões.

\section{Procedimentos metodológicos}

A investigação presente neste artigo seguiu a abordagem bibliográfica (MENDONÇA, 2017) e para a seleção do material empírico foi utilizado o buscador Google Acadêmico e o termo de busca 'jogos de linguagem e Modelagem Matemática'. 


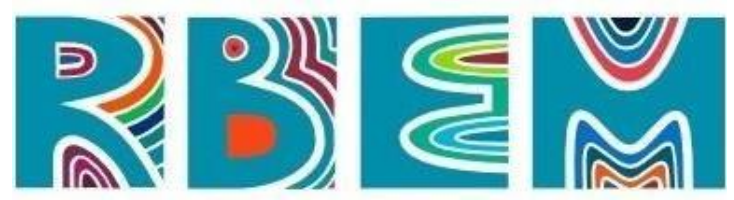

REVISTA BAIANA DE EDUCAÇÃO MATEMÁTICA

A delimitação temporal compreende o período entre os anos de 2010 e 2019, uma vez que nos interessam os trabalhos mais recentes ${ }^{3}$. Nesse período, o mecanismo de busca exibiu 14.400 resultados dispostos em 93 páginas do site, que englobavam artigos, dissertações e teses.

Diante das 93 páginas do site, a seleção do material sucedeu por meio da leitura, mais especificamente do título, resumo e das palavras-chaves dos trabalhos exibidos. Porém, o processo de seleção do material restringiu-se somente aos artigos, pois verificou-se que muitos deles são produtos de dissertações ou teses.

Apesar da exibição de grande quantidade de resultados, neste percurso de leitura e seleção do material foram encontrados trabalhos que relacionam a linguagem matemática com jogos manuais ou digitais, a matemática e a linguagem dos jogos digitais, linguagem e práticas de ensino de Matemática para estudantes surdos, linguagem de programação e Modelagem Matemática, linguagem e representações matemáticas, semiótica, cognição ou raciocínio lógico. Além destes, foram detectados trabalhos que discorrem acerca de problemas pertencentes ao campo da Educação Matemática, inclusive sobre a Modelagem Matemática, e que são tratados segundo o viés de práticas discursivas pós-estruturalistas. Porém, como estes trabalhos não possuem relação com a filosofia da linguagem de Wittgenstein, foram descartados. Também não foram considerados para a análise artigos que dissertam sobre jogos de linguagem e Etnomatemática, ou jogos de linguagem em outros contextos de ensino relacionados a outras áreas do conhecimento. Por fim, restaram dezenove artigos que versam especificamente sobre a Modelagem e a filosofia da linguagem de Wittgenstein.

Além destes, outro artigo foi localizado nos Anais da XI Conferência Nacional sobre Modelagem na Educação Matemática, a qual ocorreu em novembro de 2019. Tal busca ocorreu após a realização da pesquisa no Google Acadêmico, o que totalizou vinte artigos.

Dentre os vinte artigos, selecionou-se, para o presente estudo, por meio da leitura completa de cada um dos trabalhos, apenas aqueles cujo foco principal de discussão trata-se de algum conceito específico da Modelagem e/ou que trata das fases do desenvolvimento da Modelagem. Os artigos que restaram trazem à tona outros aspectos da filosofia da linguagem

\footnotetext{
3 Ao fazer uma rápida busca com o período entre os anos de 2000 e 2010, verificou-se que há pequena quantidade de trabalhos que tratam da filosofia da linguagem no contexto da Educação Matemática. Parece-nos vestígio importante para realização de nova busca com período maior, porém em trabalhos futuros.
} 


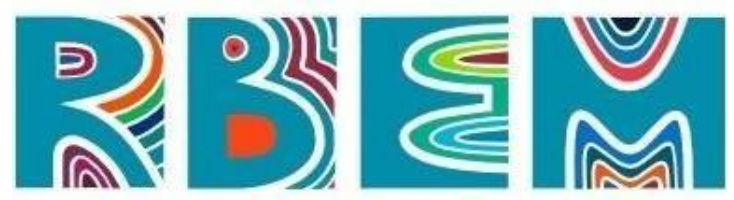

REVISTA BAIANA DE EDUCAÇÃO MATEMÁTICA

e da Modelagem que necessitam ser discutidos posteriormente, em outros trabalhos, com mais profundidade. Assim, este artigo apresenta um recorte composto por oito artigos.

Para a análise deste recorte foi fundamental examiná-lo por meio de sucessivas leituras, a fim de identificar as informações ali contidas, bem como verificar as relações existentes de acordo com o objetivo estabelecido, o que exigiu um exercício de "associação de ideias, transferência de situações, comparação de propósitos” (LIMA; MIOTO, 2007, p. 41). Foi possível organizar, assim, as informações necessárias para entender quais termos da Modelagem vêm sendo apresentados à luz do pensamento de Wittgenstein.

\section{O material empírico: da apresentação a um estudo analítico}

O Quadro 1 apresenta os resultados obtidos, configurando os artigos selecionados para o desenvolvimento do estudo:

Quadro 1: Artigos que apresentam relação entre a Modelagem e a filosofia de Wittgenstein

\begin{tabular}{|c|c|c|c|}
\hline \multicolumn{2}{|r|}{ Artigo } & Autor & Evento/Periódico \\
\hline $1^{\circ}$ & $\begin{array}{l}\text { Compreensões sobre matemática e realidade } \\
\text { na Modelagem Matemática: um estudo à luz } \\
\text { de uma perspectiva filosófica de linguagem }\end{array}$ & $\begin{array}{l}\text { Tortola, Robim e Almeida } \\
\qquad(2014)\end{array}$ & VI EPMEM \\
\hline $2^{\circ}$ & $\begin{array}{l}\text { Modelagem Matemática no Ensino } \\
\text { Fundamental: a linguagem de alunos como } \\
\text { foco de análise }\end{array}$ & Almeida e Tortola (2014) & JIEEM \\
\hline $3^{\circ}$ & $\begin{array}{l}\text { A linguagem em atividades de Modelagem } \\
\text { Matemática: caracterizações nos "Três } \\
\text { mundos da matemática" }\end{array}$ & $\begin{array}{l}\text { Robim, Tortola e Almeida } \\
\text { (2014a) }\end{array}$ & RenCiMa \\
\hline $4^{\circ}$ & $\begin{array}{l}\mathrm{O} \text { fazer Modelagem Matemática: uma } \\
\text { análise à luz da Filosofia da Linguagem }\end{array}$ & $\begin{array}{l}\text { Robim, Tortola e Almeida } \\
(2014 b)\end{array}$ & XII EPREM \\
\hline $5^{\circ}$ & $\begin{array}{l}\text { Leitura de esquemas de Modelagem numa } \\
\text { perspectiva wittgensteiniana }\end{array}$ & $\begin{array}{l}\text { Oliveira, Souza e Almeida } \\
\text { (2015) }\end{array}$ & IX CNMEM \\
\hline $6^{\circ}$ & $\begin{array}{l}\text { Modelos matemáticos em atividades de } \\
\text { Modelagem Matemática: uma terapia } \\
\text { filosófica }\end{array}$ & $\begin{array}{l}\text { Robim, Tortola e Silva } \\
\text { (2018) }\end{array}$ & VII SIPEM \\
\hline $7^{\circ}$ & $\begin{array}{l}\text { A matematização na articulação entre regras } \\
\text { e experimentação empírica em atividades de } \\
\text { Modelagem Matemática }\end{array}$ & Almeida e Sousa (2018) & VII SIPEM \\
\hline $8^{\circ}$ & $\begin{array}{l}\text { Regras, convenções e uso da matemática em } \\
\text { atividades de Modelagem Matemática }\end{array}$ & Sousa e Almeida (2019) & XI CNMEM \\
\hline
\end{tabular}

Fonte: Elaborado pelos autores (2020) 


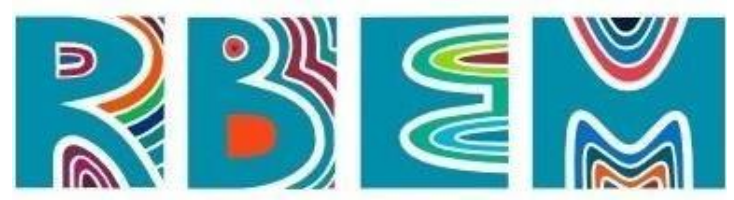

REVISTA BAIANA DE EDUCAÇÃO MATEMÁTICA

Para o desenvolvimento do estudo, os trabalhos do Quadro 1 foram organizados em dois conjuntos de acordo com semelhanças encontradas no conteúdo dos artigos. Por conseguinte, o $1^{\circ}, 5^{\circ}$ e $8^{\circ}$ artigos pertencem ao Conjunto 1 , pois tratam de conceitos da Modelagem como matemática e realidade, os quais são relacionados com usos, regras e formas de vida, conceitos da filosofia da linguagem de Wittgenstein.

O Conjunto 2 é composto pelo $2^{\circ}, 3^{\circ}, 4^{\circ}, 6^{\circ}$ e $7^{\circ}$ artigo e trata de conceitos da Modelagem relacionados às suas fases, tais como matematização e inteiração, e modelo, e estão associados aos usos e regras no contexto da filosofia da linguagem de Wittgenstein, e com a própria linguagem. Posto isto, passa-se a uma descrição sintetizada dos artigos que constituem os dois conjuntos.

Os autores do primeiro artigo, Tortola, Robim e Almeida (2014), têm como objetivo compreender os termos matemática e realidade sob a ótica da filosofia da linguagem por meio de uma atividade de Modelagem realizada no Ensino Superior. Os autores questionam o que é realidade e se a matemática pode ser uma realidade e, finalmente, como essas indagações podem ser associadas à Modelagem como prática pedagógica.

Em um primeiro momento, investigam na literatura como são apresentados os 'termos' matemática e realidade em esquemas que descrevem as etapas ${ }^{4}$ de realização da Modelagem. Eles verificam que, em alguns deles, matemática e realidade são mundos disjuntos, ou seja, a matemática não faz parte da realidade, pois os autores desses esquemas compreendem que a matemática transcende a realidade.

Em contrapartida, apontam que é muito comum a existência de narrativas em que a matemática é utilizada para tudo no cotidiano, o que implica entender que a ela faz parte da realidade. Subsequentemente, após a realização da atividade de Modelagem, eles concluem que matemática e realidade não são mundos disjuntos, como ilustrado em vários esquemas de Modelagem presentes na literatura, mas que convivem no mesmo espaço, porém, muitas vezes, com limites tênues que dependem de seus usos, por parte dos modeladores, e às suas formas de vida, as quais influenciam na interpretação da situação problema no tocante à identificação da existência de matemática naquela situação ou não, e, além disso, qual

\footnotetext{
${ }^{4}$ Considera-se como etapas da Modelagem o desenvolvimento processual das atividades de Modelagem, que possuem organização própria e pré-estipuladas.
} 


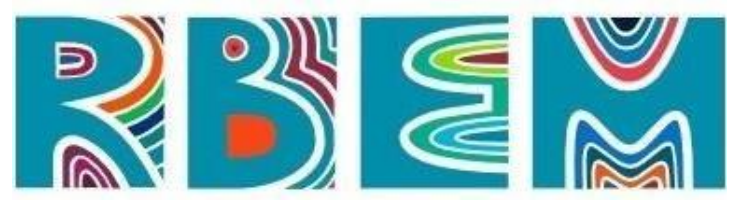

REVISTA BAIANA DE EDUCAÇÃO MATEMÁTICA

matemática se faz presente. Entende-se que, neste artigo, matemática e realidade podem, ou não, ser considerados mundos disjuntos, dependendo de seus usos e das formas de vida dos participantes do processo de Modelagem. A compreensão sobre matemática e realidade, assim, está relacionada com a maneira como eles observam esses 'mundos', e/ou segundo seus conhecimentos prévios sobre a situação em investigação que está atrelada às suas formas de vida. Pode-se dizer que a forma de vida do modelador serve como lente para observação e compreensão acerca do que seja matemática e realidade. Por conseguinte, a significação de matemática e realidade advém das formas de vida dos participantes envolvidos em determinado jogo de linguagem, que neste caso é o da Modelagem.

Assim como no primeiro artigo, os autores do quinto trabalho, Oliveira, Souza e Almeida (2015), visam compreender as relações entre os 'termos' (p. 1) matemática e realidade em esquemas de Modelagem presentes na literatura tendo em vista os usos e as formas de vida nas quais tais esquemas estão inseridos.

Oliveira, Souza e Almeida (2015) identificam que há esquemas de Modelagem que apresentam a "relação de externalidade entre matemática e realidade" (p. 11, grifo dos autores), em que o significado dos objetos matemáticos está fora da realidade, enquanto outros esquemas consideram o contrário.

Os autores deste artigo identificam que há esquemas de Modelagem nos quais existe uma relação de externalidade entre matemática e realidade, o que corrobora o que foi apontado no primeiro artigo quando afirmam que matemática e realidade podem ser consideradas mundos disjuntos. Porém, neste artigo tal relação dá-se devido às formas de vida nas quais os esquemas estão imersos, que está relacionada à concepção realista da matemática - calcada no platonismo, no qual os objetos matemáticos preexistem num mundo ideal, segundo Ponte (1997 apud OLIVEIRA; SOUZA; ALMEIDA, 2015) - ou, que não está relacionada a essa concepção em que "a matemática possui existência autônoma" (p. 11, grifo dos autores).

As autoras do oitavo artigo, Sousa e Almeida (2019), investigam o uso de regras e convenções matemáticas em atividades de Modelagem que foram desenvolvidas por estudantes do Ensino Superior. Segundo as autoras, a Modelagem permite que o uso de regras e convenções articule situações da realidade e a matemática, o que implica em uma concepção pragmática para os usos da matemática, de tal modo que é no desenvolvimento da 


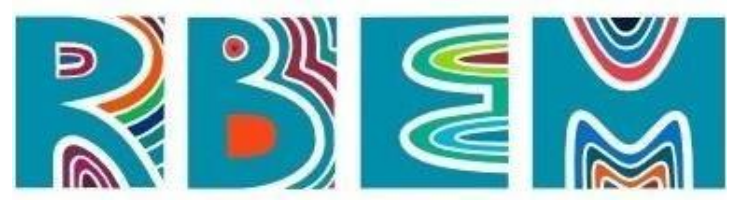

REVISTA BAIANA DE EDUCAÇÃO MATEMÁTICA

atividade de Modelagem que os alunos entram em contato com a matemática que já aprenderam ou que lhes será ensinada.

No que se refere ao Conjunto 2, os autores do segundo artigo, Almeida e Tortola (2014), investigam a relação do uso da linguagem natural e da matemática em atividades de Modelagem elaboradas por estudantes do $4^{\circ}$ ano do Ensino Fundamental. Os autores atestam que os símbolos matemáticos "ganham vida" (Wittgenstein (1994) apud Almeida e Tortola (2014)) por meio da necessidade de seus usos nas atividades de Modelagem. Além disso, as formas de vida dos alunos e a linguagem matemática com que eles estão familiarizados neste nível de escolaridade influenciam suas ações ao modelar. Então, o uso da linguagem natural e a matemática está estritamente relacionado com a forma de vida dos estudantes. Sobretudo, a Modelagem possibilita que o aluno se aproxime das regras matemáticas e dá seguridade quanto aos seus usos.

Ainda entende-se que, para os autores, os usos da linguagem sustentam e direcionam as ações dos alunos no estudo dos problemas e na busca de respostas, no sentindo de que, ao estudante matematizar uma situação/um fenômeno, ele pode constatar que determinada representação matemática não é adequada para a situação/o fenômeno em estudo. Por conseguinte, ele terá que buscar outra maneira para representá-lo sob a linguagem matemática, ou seja, precisará matematizar de outra forma.

No terceiro artigo, os autores Robim, Tortola e Almeida (2014a) tratam de diferenciações da linguagem em uma atividade de Modelagem elaborada no Ensino Superior, e como tais diferenciações conduzem o aluno para que ele transite nos Três Mundos da Matemática: Conceitual Corporificado, Simbólico Proceitual e Axiomático Formal, que “[...] referem-se a três modos diferentes de operar com os objetos matemáticos, no sentido de representar e lidar com os mesmos" (TALL, 2004a apud ROBIM; TORTOLA; ALMEIDA, 2014a, p. 5).

Segundo os autores, os Três Mundos da Matemática estão associados à linguagem, seus usos e ao desenvolvimento cognitivo dos estudantes, que utilizam diferentes linguagens na problematização, de tal forma que o uso dessas linguagens indica o modo como eles transitam por esses três mundos. No Mundo Conceitual Corporificado eles lidam com as informações obtidas referente à situação/ao fenômeno em investigação, valendo-se das linguagens tabular, gráfica e natural. O Mundo Simbólico Proceitual está relacionado à fase 


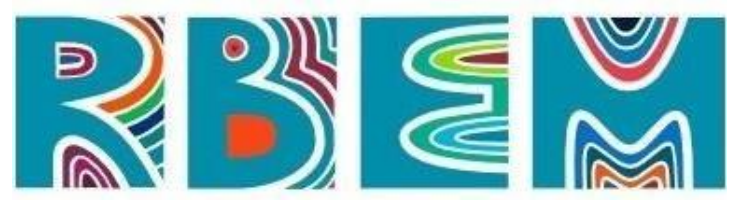

REVISTA BAIANA DE EDUCAÇÃO MATEMÁTICA

da matematização, em que o aluno usa a linguagem aritmética ou algébrica e operações matemáticas. Para obter o modelo matemático, os estudantes refinam a manipulação dos símbolos matemáticos "passando a usá-los como processos e conceitos" (ROBIM; TORTOLA; ALMEIDA, 2014a, p. 14), então há a interação entre o Mundo Simbólico Proceitual e o Mundo Axiomático Formal.

Os autores do quarto artigo, Robim, Tortola e Almeida (2014b), analisam como os alunos trabalham com regras matemáticas em atividades de Modelagem que foram realizadas no Ensino Superior. Eles discorrem que o uso de regras matemáticas na Modelagem normatiza os procedimentos dos alunos na busca pelo modelo matemático. Assim, as regras matemáticas norteiam a ação dos estudantes no processo de elaboração do modelo, no sentido de que eles trabalham objetivando a regra adequada para a situação/o fenômeno em estudo, e isso depende dos seus usos, ao modelar, no jogo de linguagem da Modelagem. Os autores entendem que, "Segundo Wittgenstein, o aprendizado dessas regras só faz sentido dentro de uma prática, de uma forma de vida, em um jogo de linguagem. E é nesse jogo, que a linguagem ganha sentido. Ou seja, é usando a linguagem que se aprende a usá-la" (ROBIM; TORTOLA; ALMEIDA, 2014b, p.15).

São apercebidas semelhanças entre o segundo e o quarto artigo, pois em ambos tratase sobre o uso, seja da linguagem ou de regras matemáticas, sendo que a regra matemática é a linguagem desempenhando a função normativa (GOTTSCHALK, 2008). Portanto, a linguagem direciona a ação do estudante no processo de matematização, e isto é observado quando ele consegue constatar que determinada regra matemática é ou não adequada para representar a situação/o fenômeno que está sob investigação no processo de Modelagem.

Os autores do sexto artigo, Robim, Tortola e Silva (2018), utilizam a terapia de Wittgenstein como um método para tratar confusões conceituais em atividades de Modelagem realizadas por estudantes do Ensino Superior, com o objetivo de trazer explicações referentes ao uso de modelos descritivo, prescritivo e explicativo, os quais têm como função descrever, explicar ou predizer acerca de situações/fenômenos.

Segundo os autores, os usos descritivo, prescritivo e explicativo podem ser identificados, inclusive, em fases ${ }^{5}$ da Modelagem, como na inteiração e matematização. Além disso, aspectos dos fenômenos/das situações preservadas na formulação de hipóteses e

\footnotetext{
5 A expressão “fases da Modelagem” é considerada como sinônimo de "etapas da Modelagem”.
} 


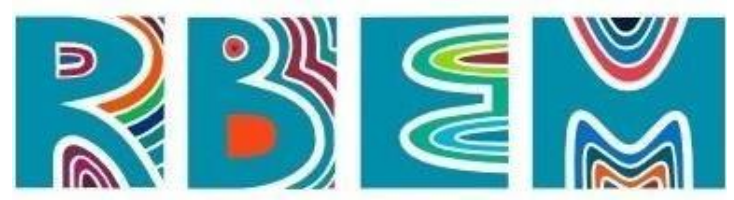

REVISTA BAIANA DE EDUCAÇÃO MATEMÁTICA

nos dados normatizam os usos que os alunos fazem de estruturas matemáticas que constituirão os diferentes tipos de modelos.

No sétimo artigo, Almeida e Sousa (2018) analisam uma atividade de Modelagem elaborada por alunos do Ensino Superior para investigar como as regras e a experimentação empírica são articuladas na matematização. Os alunos matematizam a partir de relações estabelecidas entre a experimentação empírica e os conceitos matemáticos que são jogos de linguagem diferentes. As autoras também apontam que não se está advogando pela existência de significações extralinguísticas para os conceitos matemáticos, as quais poderão ser descobertas ou construídas pelos alunos nas atividades de Modelagem, mas que o processo de Modelagem direciona o uso de regras matemáticas articuladas com justificativas e a experimentação empírica.

O fato de a Modelagem direcionar o uso de regras matemáticas corrobora o que é evidenciado pelo segundo e quarto artigos. As autoras ressaltam que as relações estabelecidas entre a experimentação empírica, os conceitos matemáticos e as regras permitem matematizar a situação em investigação. Portanto, assim como no primeiro e quarto artigos, entende-se que o sétimo também trata do uso de regras na Modelagem, sendo que são elas que direcionam as ações do aluno na fase da matematização.

\section{Análises}

Diante do exposto, o material empírico evidencia termos no âmbito da Modelagem, tais como matemática e realidade, modelo, matematização e inteiração, que se entrelaçam a conceitos da filosofia da linguagem, como usos, formas de vida, regras e a própria linguagem, ou seja, há uma relação entre os termos da Modelagem e aspectos da filosofia da linguagem.

Os autores dos dois primeiros trabalhos do Conjunto 1 se preocupam com a relação entre matemática e realidade, então questionam o que é a realidade e se a matemática faz parte da realidade ou não. Eles constatam que há, na literatura, esquemas de Modelagem em que a matemática é percebida sob perspectiva platônica, idealista, na qual os objetos matemáticos preexistem em um mundo ideal e que, deste modo, matemática e realidade constituem 'mundos' diferentes. Por outra parte, ao realizar atividades de Modelagem com os estudantes, os autores detectam que os alunos conseguem vislumbrar a matemática presente 


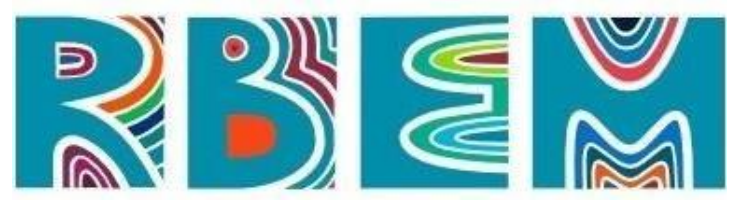

REVISTA BAIANA DE EDUCAÇÃO MATEMÁTICA

na realidade. Então, pode-se dizer que a Modelagem permite que o aluno identifique a matemática na realidade, porém existem condições para que isso aconteça. Verifica-se que a identificação da matemática numa situação/num fenômeno real depende do conhecimento matemático prévio do aluno, o que também está atrelado ao nível de escolaridade em que ele se encontra, o que se refere à forma de vida deste estudante.

Por conseguinte, a significação de matemática e realidade advém das formas de vida dos participantes envolvidos em determinado jogo de linguagem, que neste caso é o da Modelagem (MARON, 2017). Ademais, quando são analisados esquemas de Modelagem encontrados na literatura, a significação de matemática emerge de uma forma de vida da própria matemática, que pode ser idealista, na qual o esquema está inscrito.

Além disso, as regras e as convenções matemáticas favorecem a descrever matematicamente uma situação/um fenômeno real, conforme indica o terceiro artigo do Conjunto 1. Então, entende-se que, na medida que o estudante avança no conhecimento do jogo de linguagem da matemática, ele se apodera de regras e convenções desse jogo de linguagem, no sentido de que elas passam a fazer parte da sua forma de vida e favorecem sua leitura e identificação da matemática presente na realidade.

Portanto, entende-se que, por meio do Conjunto 1, é possível vislumbrar possíveis relações entre os termos matemática e realidade, usos, formas de vida e regras no contexto da filosofia do segundo Wittgenstein.

No que tange ao Conjunto 2, a tônica são os usos de regras matemáticas em atividades de Modelagem, de maneira que tais regras direcionam as ações dos estudantes no processo de Modelagem, ou seja, quando eles estão trabalhando nas fases dessa atividade.

O uso de regras matemáticas nas atividades de Modelagem permite que os estudantes testem se de fato determinada regra é adequada ou não para o fenômeno/a situação real em investigação. Além disso, o uso das regras está associado às formas de vida dos estudantes.

Portanto, o recorte realizado favorece uma discussão de conceitos da Modelagem em seu próprio contexto linguístico, isto é, no contexto da Modelagem, o que está de acordo com Wittgenstein (1994) quando o autor afirma que o significado não está no próprio objeto, mas é definido a posteriori, isto é, por meio dos seus usos.

É importante ressaltar, como aponta Costa (2019), que os termos mobilizados se referem a questões muito importantes no contexto da Modelagem e que se encontram em 


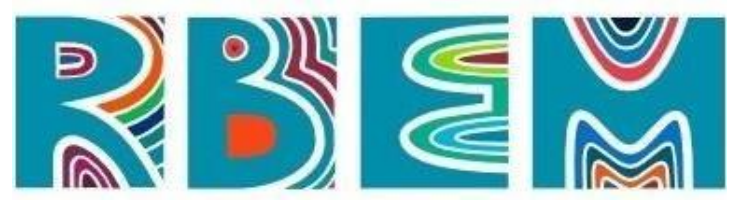

REVISTA BAIANA DE EDUCAÇÃO MATEMÁTICA

pleno movimento de discussão, por exemplo, quando se fala em realidade, termo este definido discursivamente como centralidade, ponto de partida das atividades. A autora se pergunta, entretanto: que realidade seria esta?, uma vez que há, no discurso da Modelagem, discussões (NEGRELLI, 2008; ARAÚJO, 2007; ANASTÁCIO, 1990; DUARTE, 2009; ROCHA, 2015) que "buscam determiná-la, nomeá-la, torná-la mais 'palpável', o que demonstra a sua complexidade". (COSTA, 2019, p. 9).

Deste modo, entende-se que o uso destas palavras, ou termos, está sendo explorado dentro do seu contexto linguístico, que neste caso é o contexto da Modelagem, de tal maneira que é na atividade, ou seja, 'ao modelar', que é possível detectar como os modeladores articulam, como usam as palavras/os termos (matemática, realidade, modelo, matematização, inteiração, inclusive as regras matemáticas e os diferentes tipos de linguagem), o que lhes permite compreender melhor seus significados.

Isso quer dizer que a Modelagem se organiza de um modo que, ao mobilizar as palavras matemática, realidade, modelo, matematização e inteiração, no contexto da atividade de Modelagem, emergem as possibilidades de uma melhor compreensão para sua significação e definição de conceitos, o que permite "organizar a experiência" (GOTTSCHALK, 2007) dos modeladores, pesquisadores da área da Modelagem e estudantes. Em vista disso, o Conjunto 2 implica uma reflexão sobre usos, regras e a própria linguagem e as relações com fases da Modelagem, tais como matematização e inteiração, e modelo.

\section{Considerações finais}

Este estudo evidencia os usos de termos que pertencem ao âmbito da Modelagem. Por meio da pesquisa realizada, entende-se que são explorados os usos de tais termos dentro de seu contexto linguístico, que neste caso é o da Modelagem, com vistas a uma melhor compreensão de seus significados.

Os termos matemática, realidade, modelo, matematização e inteiração adquirem sentido por meio dos seus usos, ou então, os sentidos possuem uma relação de dependência com seus usos em determinado contexto linguístico, que neste caso é o da Modelagem ou, ainda, com a Modelagem considerada como um jogo de linguagem, possibilitando, inclusive, outra maneira de compreendê-la. 


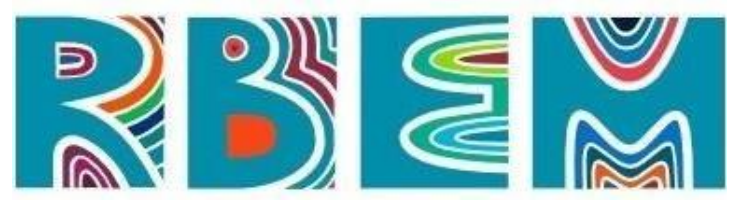

REVISTA BAIANA DE EDUCAÇÃO MATEMÁTICA

Além disso, constata-se que as ações dos modeladores no processo de realização da Modelagem são reguladas de acordo com regras, convenções matemáticas e a sua forma de vida, no sentido de que as formas de vida têm uma relação com o conhecimento prévio do estudante quanto à matemática e/ou à situação da realidade que está sendo investigada por ele.

Em vista disso, entende-se que a mobilização dos termos matemática, realidade, modelo, inteiração e matematização no âmbito da Modelagem, sob a perspectiva da filosofia do segundo Wittgenstein, possibilita reconfigurar e reajustar os significados que são atribuídos aos próprios termos, como uma maneira de dar visibilidade a uma outra forma de perceber a Modelagem, colocando em suspensão o caráter único não só da Modelagem, mas de conceitos específicos que a constituem e fazem dela a sua essência.

Isso significa que o entrelaçamento discursivo entre o campo da Filosofia, da Pedagogia e da Educação Matemática possibilitaria uma outra organização prática - e discursiva - da Modelagem, uma vez que é "preciso em cada caso aprender não apenas $o$ que se pode dizer sobre um objeto, mas sim como se tem falado dele" (WITTGENSTEIN, 2009b, p. 81, grifos do autor), já que é justamente aquilo que se diz - discurso - sobre Modelagem que possibilita a sua constituição e criação.

Essa outra maneira de compreender a Modelagem pode reconfigurar os significados atribuídos aos próprios conceitos da Modelagem, entendendo-a como um campo teórico em constante movimento, sempre dinâmico.

\section{Referências}

ALMEIDA, Lourdes Maria Werle de; TORTOLA, Emerson Modelagem Matemática no Ensino Fundamental: a linguagem de alunos como foco de análise. JIEEM - Jornal Internacional de Estudos em Educação Matemática, São Paulo, v. 7, n. 1, p. 111-142, 2014.

ALMEIDA, Lourdes Maria Werle de; SOUSA, Bárbara Nivalda Palharini Alvim. A matematização na articulação entre regras e experimentação empírica em atividades de Modelagem Matemática. In: VII SEMINÁRIO INTERNACIONAL DE PESQUISA EM EDUCAÇÃO MATEMÁTICA, 7º, 2018, Foz do Iguaçu. Anais... Foz do Iguaçu: SIPEM, 2018. p. 1-13.

ANASTÁCIO, Maria Queiroga Amoroso. Considerações sobre a modelagem matemática e a educação matemática. 1990. 100f. Dissertação (Mestrado em Educação Matemática) Instituto de Geociências e Ciências Exatas, Universidade Estadual Paulista, Rio Claro, 1990. 


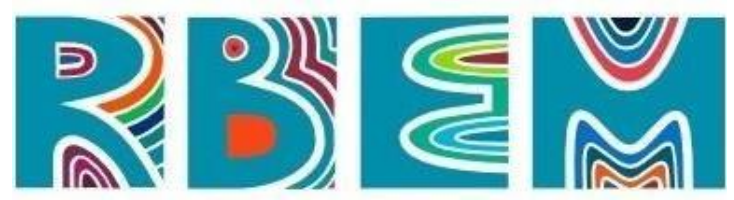

REVISTA BAIANA DE EDUCAÇÃO MATEMÁTICA

ARAÚJO, Inês Lacerda. Do signo ao discurso: introdução à filosofia da linguagem. São Paulo: Parábola Editorial, 2004. 279p.

ARAÚJO, Jussara Loiola. Relação entre matemática e realidade em algumas perspectivas de modelagem matemática na educação matemática. In: BARBOSA, J. C; CALDEIRA, A. D.; ARAÚJO, J. L. (Org.). Modelagem matemática na educação matemática brasileira: pesquisas e práticas educacionais. Recife: Sociedade Brasileira de Educação Matemática, 2007. p. 17-32.

BARBOSA, Jonei Cerqueira. Modelagem matemática: concepções e experiências de futuros professores. 2001. 194f. Tese (Doutorado em Educação Matemática) - Instituto de Geociências e Ciências Exatas, Universidade Estadual Paulista, Rio Claro, São Paulo, 2001.

CALDEIRA, Ademir Donizeti; MAGNUS, Maria Carolina Machado; CAMBI, Betina. Modelagem Matemática na Educação Matemática: uma engrenagem da maquinaria curricular. Revista de Educação, Ciência e Cultura, Canoas, v. 23, n. 1, p. 27-39, mar. 2018.

COSTA, Daniana de. Jogos de linguagem no contexto da Modelagem Matemática: quais mobilizações? Primeiras aproximações. In: XI CONFERÊNCIA NACIONAL SOBRE MODELAGEM NA EDUCAÇÃO MATEMÁTICA, 11º, 2019, Belo Horizonte: Anais... Belo Horizonte: XI CNMEM, 2019, p. 1-12.

DUARTE, Claudia Glavam. A "realidade" nas tramas discursivas da educação em matemática escolar. 2009. 198f. Tese (Doutorado em Educação) - Programa de PósGraduação em Educação, Universidade do Vale do Rio dos Sinos - UNISINOS, São Leopoldo, RS, 2009.

DUARTE, Claudia Glavam; TASCHETTO, Leonidas Roberto. Reverberações da filosofia wittgensteiniana na Educação Matemática. In: DUARTE, Claudia Glavam; MOURA, Josiane de; SANTOS, Suelen Assunção (org.). Com(posições) Pós Estruturalistas em Educação Matemática e Educação em Ciências. São Paulo: Pimenta Cultural, 2019. p. 51-70.

FOUCAULT, Michel. Sobre as maneiras de se escrever a história. In: Arqueologia das ciências e história dos sistemas de pensamento. Ditos e Escritos II. Organização e seleção de textos Manoel Barros da Motta: tradução Elisa Monteiro. 3. ed. Rio de Janeiro: Forense Universitária, 2013. p. 64-80.

FOUCAULT, Michel. A ordem do discurso: aula inaugural no Collège de France, pronunciada em 2 de dezembro de 1970. Trad. Laura Fraga de Almeida Sampaio. 24. ed. São Paulo: Edições Loyola, 2014. 74p.

GOTTSCHALK, Cristiane Maria Cornelia. Uma concepção pragmática de ensino e aprendizagem. Educação e Pesquisa, São Paulo, v. 33, n. 3, p. 459-470, set./dez. 2007. 


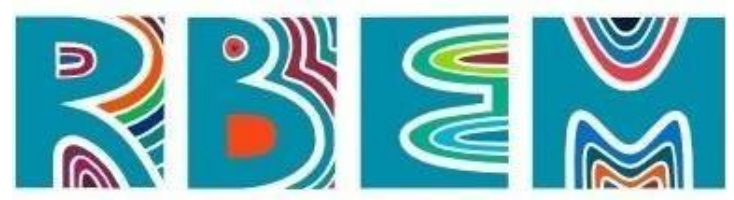

REVISTA BAIANA DE EDUCAÇÃO MATEMÁTICA

GOTTSCHALK, Cristiane Maria Cornelia. A construção e transmissão do conhecimento matemático sob uma perspectiva wittgensteiniana. Cad. Cedes, Campinas, v. 28, n. 74, p. 7596, 2008.

GOTTSCHALK, Cristiane Maria Cornelia. A perspectiva antropológica filosófica de Wittgenstein e o conceito de homem na educação. International Studies on Law and Education, CEMOrOc-Feusp/IJI-Univ. do Porto, mai-ago, 2016.

LIMA, Telma. Cristiane Sasso de; MIOTO, Regina Célia Tamasso. Procedimentos Metodológicos na construção do conhecimento científico: a pesquisa bibliográfica. Revista Katálysis (Impresso), v. 10, p. 35-45, 2007.

MARCONDES, Danilo. Iniciação à história da filosofia: dos pré-socráticos a Wittgenstein. 6. ed. Rio de Janeiro: Jorge Zahar, 2009.

MAGNUS, Maria Carolina Machado. Modelagem matemática na educação matemática brasileira: histórias em movimento. 2018. 227f. Tese (Doutorado em Educação) - Programa de Pós-Graduação em Educação, Universidade Federal de São Carlos, São Carlos, 2018.

MAGNUS, Maria Carolina Machado; CALDEIRA, Ademir Donizeti; DUARTE, Claudia Glavam. O enunciado "é importante formar sujeitos críticos e reflexivos" nas tramas discursivas da modelagem matemática: uma problematização. Educ. Matem. Pesq., São Paulo, v. 21, n. 2, p. 23-43, 2019.

MARON, Cristianne do Rocio de Mello. Modelagem Matemática como jogo de linguagem. 2017. 172p. Dissertação (Mestrado em Educação Matemática). Universidade Federal do Paraná, Curitiba, 2017.

MENDONÇA, Priscilla Bibiano de Oliveira. A metodologia científica em pesquisas educacionais: pensar e fazer ciência. Interfaces Científicas - Humanas e Sociais, v. 5, p. 87, 2017.

MORENO, Arley Ramos. Wittgenstein: os labirintos da linguagem ensaio introdutório. São Paulo: Moderna, Campinas, 2000. Coleção logos. 112p.

MORENO, Arley Ramos. Wittgenstein: através das imagens. 2. ed. Campinas: Editora Unicamp, 1995. Coleção Repertórios. 142p.

NEGRELLI, Leônia Gabardo. Uma reconstrução epistemológica do processo de modelagem matemática para a educação (em) matemática. 2008. 94f. Tese (Doutorado em Educação) Setor de Educação, Universidade Federal do Paraná, Curitiba, 2008.

OLIVEIRA, Camila Fogaça; SOUZA, Henrique Cristiano Thomas; ALMEIDA, Lourdes Maria Werle de. Leituras de esquemas de modelagem matemática numa perspectiva wittgensteiniana. In: IX CONFERÊNCIA NACIONAL SOBRE MODELAGEM NA 


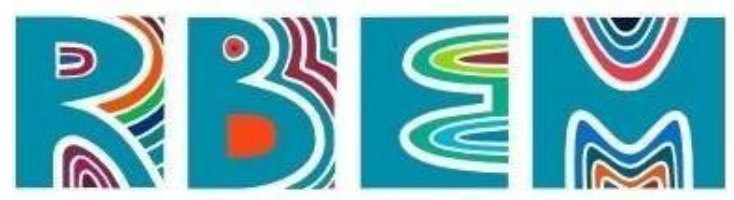

REVISTA BAIANA DE EDUCAÇÃO MATEMÁTICA

EDUCAÇÃO MATEMÁTICA, 9ª 2015, São Carlos. Anais... São Carlos: IX CNMEM, 2015, p. 1-14.

QUARTIERI, Marli Teresinha; KNIJNIK, Gelsa. Modelagem Matemática na Escola Básica: surgimento e consolidação. Caderno pedagógico, Lajeado, v. 9, n. 1, p. 9-26, 2012.

ROBIM, Bárbara Nivalda Palharini Alvim Sousa; TORTOLA, Emerson; ALMEIDA, Lourdes Maria Werle de. A linguagem em atividades de Modelagem Matemática: caracterizações nos "Três mundos da matemática". REnCiMa-Revista de Ensino de Ciências e Matemática, São Paulo, v. 5, n. 1, 2014a, p. 1-20.

ROBIM, Bárbara Nivalda Palharini Alvim Sousa; TORTOLA, Emerson; ALMEIDA, Lourdes Maria Werle de. O fazer Modelagem Matemática: uma análise à luz da Filosofia da Linguagem. In: XII ENCONTRO PARANAENSE DE EDUCAÇÃO, 12², 2014, Campo Mourão. Anais... Campo Mourão: XII EPREM, 2014b, p. 2-17.

ROBIM, Bárbara Nivalda Palharini Alvim Sousa; TORTOLA, Emerson; SILVA, Cíntia da. Modelos matemáticos em atividades de Modelagem Matemática: uma terapia filosófica. In: VII SEMINÁRIO INTERNACIONAL DE PESQUISA EM EDUCAÇÃO MATEMÁTICA, 8 , 2018, Foz do Iguaçu. Anais... Foz do Iguaçu: VII SIPEM, 2018, p. 1-13.

ROCHA, Ana Paula Francisca Pires. Realidade, matemática e modelagem: as referências feitas pelos alunos. 2015. 187f. Dissertação (Mestrado em Educação). Programa de PósGraduação em Educação: Conhecimento e Inclusão Social, da Faculdade de Educação da Universidade Federal de Minas Gerais, Belo Horizonte, 2015.

ROSA, Claudia. Carreira. Formação continuada de professores, Modelagem Matemática e professor reflexivo: uma experiência. In: XI ENCONTRO NACIONAL DE EDUCAÇÃO MATEMÁTICA, 11º 2013, Curitiba. Anais... Curitiba: XI ENEM, 2013.

SOUSA, Bárbara Nivalda Palharini Alvim; ALMEIDA, Lourdes Maria Werle de. Regras, convenções e o uso da matemática em atividades de modelagem matemática. In: XI CONFERÊNCIA NACIONAL SOBRE MODELAGEM NA EDUCAÇÃO MATEMÁTICA, 11º, 2019, Belo Horizonte. Anais... Belo Horizonte: XI CNMEM, 2019, p. 1-15.

TORTOLA, Emerson; ROBIM, Bárbara Nivalda Palharini Alvim Sousa; ALMEIDA, Lourdes Maria Werle de. Compreensões sobre matemática e realidade na Modelagem Matemática: um estudo à luz de uma perspectiva filosófica de linguagem. In: VI ENCONTRO PARANAENSE DE MODELAGEM NA EDUCAÇÃO MATEMÁTICA, $7^{\circ}$, 2014, Curitiba. Anais... Curitiba: VI EPMEM, 2014, p. 1-18.

VEIGA-NETO, Alfredo. Foucault \& a Educação. 2. ed. Belo Horizonte: Autêntica, 2014, $160 \mathrm{p}$. 


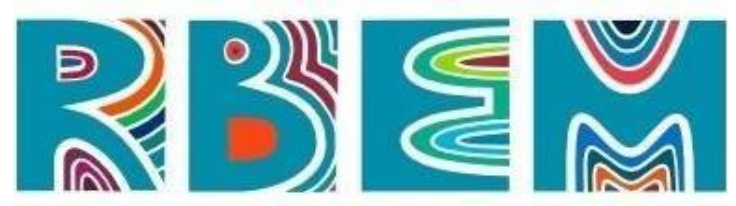

VILELA, Denise Silva; MENDES, Jackeline Rodrigues. A linguagem como eixo de pesquisa em educação matemática: contribuições da filosofia e estudos do discurso. Zetetiké, Campinas, v. 19, n. 36, p. 7-25, 2011.

WITTGENSTEIN, Ludwig. Investigações filosóficas. Tradução Marcos G. Montagnoli. 6. ed. Petrópolis: Vozes, 2009a. 350p.

WITTGENSTEIN, Ludwig. Anotações sobre as cores. Campinas, SP: Editora da Unicamp, 2009b, 208p.

Artigo submetido em: 07/08/2020

Artigo aceito em: 14/08/2020 